Pesq. Vet. Bras. 28(11):555-560, novembro 2008

\title{
Effects of laparoscopy on the cardiorespiratory system of brown brocket deer (Mazama gouazoubira) anesthetized with ketamine/ xylazine/ midazolam combination and isoflurane ${ }^{1}$
}

\author{
Marina Salles Munerato2*, Eveline dos Santos Zanetti ${ }^{3}$, José Antônio \\ Marques $^{2}$ and José Maurício Barbanti Duarte ${ }^{3}$
}

\begin{abstract}
Munerato M.S., Zanetti E.S., Marques J.A. \& Duarte J.M.B. 2008. Effects of laparoscopy on the cardiorespiratory system of brown brocket deer (Mazama gouazoubira) anesthetized with ketamine/ xylazine/ midazolam combination and isoflurane. Pesquisa Veterinária Brasileira 28(11):555-560. Departamento de Clínica e Cirurgia Veterinária, Faculdade de Ciências Agrárias e Veterinárias, Universidade Estadual Paulista, Via de Acesso Professor Paulo Donato Castellane s/n, Jaboticabal, SP 14884-900, Brazil. E-mail: marinamunerato @gmail.com

Laparoscopy is not widely used as a tool to perform assisted reproduction techniques in South American cervids; thus, scarce information in literature is available regarding its effects and appropriate anesthetic protocols to perform it. This study evaluated the effect of laparoscopy on heart rate $(\mathrm{HR})$, respiration rate $(\mathrm{RR})$, saturation of oxyhemoglobin $\left(\mathrm{SpO}_{2}\right)$ and rectal temperature (RT) of six female brown brocket deer (Mazama gouazoubira) anesthetized with ketamine $(5 \mathrm{mg} / \mathrm{kg})$, xylazine $(0.3 \mathrm{mg} / \mathrm{kg})$, midazolam $(0.5 \mathrm{mg} / \mathrm{kg})$ combination i.v. and isoflurane. Twelve laparoscopies were performed and each animal was used twice with a 40-day interval. After anesthetized, the animals were placed in dorsal recumbency to perform laparoscopy procedure using abdominal $\mathrm{CO}_{2}$ insufflations $(14.2 \pm 2.39 \mathrm{mmHg} ; \mathrm{M} \pm \mathrm{SE})$. The main events of the laparoscopy procedure were divided into three periods: animal without (P1) and with abdominal insufflation (P2) and abdominal insufflation with the hips raised at $45^{\circ}(\mathrm{P} 3)$. As a control, the animals were anesthetized again 40 days after the last laparoscopy, and were maintained in a dorsal recumbency for the same average duration of the previous anesthesia and no laparoscopy procedure was conducted. The period of anesthesia for the controls was also divided into $\mathrm{P} 1, \mathrm{P} 2$, and $\mathrm{P} 3$ considering the average duration of these periods in previous laparoscopies performed. Data were analyzed through the (ANOVA) variance analysis followed by Tukey test and values at $\mathrm{P}<0.05$ were considered significant. No significant differences were observed in the parameters evaluated at P1, P2 and P3 between the animals submitted to laparoscopy and control. However, the RR mean between P1 (38.8 $\pm 4.42)$ and $\mathrm{P} 3(32.7 \pm 4.81)$; and the RT mean between the $\mathrm{P} 1\left(38.2^{\circ} \mathrm{C} \pm 0.17\right), \mathrm{P} 2$ $\left(37.6^{\circ} \mathrm{C} \pm 0.19\right)$ and $\mathrm{P} 3\left(37.0^{\circ} \mathrm{C} \pm 0.21\right)$ varied significantly, independent of the laparoscopy. These data indicated that laparoscopy didn't cause any significant alterations in the cardiorespiratory parameters evaluated, even though the anesthetic protocol used can cause a reduction in the RT contributing to development of hypothermia during anesthesia.

INDEX TERMS: Abdominal insufflation, capnoperitoneum, cervids, inhalatory anesthesia.
\end{abstract}

\footnotetext{
${ }^{1}$ Received on May 1, 2008.

Accepted for publication on September 30, 2008.

Financial support from Fundação de Amparo à Pesquisa do Estado de São Paulo (FAPESP).

${ }^{2}$ Departamento de Clínica e Cirurgia Veterinária, Faculdade de Ciên-
}

cias Agrárias e Veterinárias (FCAV), Universidade Estadual Paulista (Unesp), Via de Acesso Professor Paulo Donato Castellane $s / n$, Jaboticabal, SP 14884-900, Brazil. ${ }^{*}$ Corresponding author: marinamunerato@gmail.com

${ }^{3}$ Departamento de Zootecnia, FCAV, Unesp, Jaboticabal, SP. 
RESUMO.- [Efeitos da laparoscopia sobre o sistema cardiorrespiratório de veados-catingueiro (Mazama gouazoubira) anestesiados com a associação cetamina/xilazina/midazolam e isofluorano.] A laparoscopia ainda é pouco utilizada como ferramenta para técnicas de reprodução assistida em cervídeos sul-americanos, não havendo informações sobre seus efeitos e protocolos anestésicos seguros para sua realização. Objetivaramse avaliar as possíveis alterações na freqüência cardíaca (FC), respiratória (FR), saturação de oxihemoglobina (SpO2) e temperatura retal (TR) durante a laparoscopia para visualização dos órgãos reprodutivos de seis fêmeas de veado-catingueiro (Mazama gouazoubira) anestesiadas com a associação cetamina $(5 \mathrm{mg} / \mathrm{kg})$, xilazina $(0,3 \mathrm{mg} / \mathrm{kg})$, midazolam $(0,5 \mathrm{mg} / \mathrm{kg})$ e isofluorano. Cada animal, após anestesiado, foi posicionado em decúbito dorsal para realização de duas laparoscopias com insuflação abdominal de $\mathrm{CO}_{2}(14,2 \pm 2,39 \mathrm{mmHg}$; $\mathrm{M} \pm$ EPM) com intervalo de 40 dias. Para avaliar os principais eventos da laparoscopia, esta foi dividida em três períodos: animal sem insuflação abdominal (P1), com insuflação abdominal (P2) e insuflação abdominal com os quadris elevados a $45^{\circ}(\mathrm{P} 3)$. O controle foi realizado após 40 dias da última laparoscopia, para isto, cada animal foi novamente anestesiado e mantido em decúbito dorsal por um período de tempo igual ao tempo médio de duração das anestesias realizadas nas laparoscopias, sem que o procedimento laparoscópico fosse realizado. O tempo de anestesia dos controles foi também dividido em P1, P2 e P3, respeitando o tempo médio de duração de cada um destes períodos das laparoscopias. Para análise dos dados foi usado o teste de análise de variância (ANOVA) seguido do teste de Tukey e valores de $\mathrm{P}<0,05$ considerados significativos. Não houve diferença significativa nos parâmetros estudados em nenhum dos períodos estabelecidos para o controle e laparoscopia. Porém, a FR média entre P1 $(38,8 \pm 4,42)$ e P3 $(32,7 \pm 4,81)$ e a TR média entre $\mathrm{P} 1\left(38,2^{\circ} \mathrm{C} \pm 0,17\right), \mathrm{P} 2\left(37,6^{\circ} \mathrm{C} \pm 0,19\right)$ e $\mathrm{P} 3\left(37,0^{\circ} \mathrm{C}\right.$ $\pm 0,21)$ variaram significativamente, independente da laparoscopia. Tais dados permitiram concluir que a laparoscopia não promoveu alterações significativas nos parâmetros avaliados, embora o protocolo anestésico utilizado tenha contribuído para redução da temperatura retal resultando em risco de hipotermia durante a anestesia.

TERMOS DE INDEXAÇÃO: Insuflação abdominal, capnoperitônio, cervídeos, anestesia inalatória.

\section{INTRODUCTION}

The use of assisted reproduction techniques for deer conservation is an alternative since one third of deer species, found in the world, are currently considered rare or endangered (Berg \& Asher 2003). Laparoscopy is a low invasive procedure, if compared with laparotomy, and it has been the preferential surgical technique to visualize female's reproductive tract and conduct some assisted reproduction techniques (Duke et al. 2002, Posner et al.
2005, Hendrix 2006). For this reason, the laparoscopic technique requires that the animal be positioned in dorsal recumbence and the abdomen insufflated with gases such as $\mathrm{CO}_{2}$, which is the most commonly used for this practice (Quandt 1999, Hendrix 2006). Moreover, the animal's hips should be raised between $30^{\circ}$ to $45^{\circ}$ by using an adjustable surgical table to visualize the female's reproductive tract (Sumar \& Bravo 1991, Asher et al 1999).

Laparoscopy has been used as a tool to conduct assisted reproduction techniques in countries where some species of deer are raised commercially and animals are usually sedated with $\alpha-2$ agonist drugs or anesthetized with these drugs associated with dissociative drugs during the procedure (Willard et al. 1998, Asher et al 1999). However, just a few studies have been reported in the literature about the use of laparoscopy for South American cervids (Posner et al. 2005). Moreover, the high cost, the professional requirements to perform laparoscopy (Willard et al. 1998), and the limited number of animals in captivity associated with the fact that they are known to be very sensitive to stress and difficult to handle (Dias 1997) are factors that make studies with South American deer difficult.

In Brazil, the brown brocket (Mazama gouazoubira) is the most abundant species of deer in captivity and for this reason has been used as an experimental model in experiments that aims to evaluate reproduction techniques used as a tool for conservation (Zanetti 2006).

The objective of this study was to evaluate the effect of laparoscopy on the heart rate $(H R)$, respiration rate $(R R)$, saturation of oxyhemoglobin $\left(\mathrm{SpO}_{2}\right)$ and rectal temperature (RT) of six female brown brocket deer anesthetized with ketamine/xylazine/midazolam combination and maintenance of anesthesia with isoflurane.

\section{MATERIALS AND METHODS}

This study was approved by the Animal Ethics and Welfare Committee (CEBEA, Comitê de Ética e Bem-Estar Animal) of the Faculdade de Ciências Agrárias e Veterinárias (FCAV), Unesp, Jaboticabal, SP, Brazil. Six adult female brown brocket deer from the Deer Research and Conservation Center (Nupecce, Núcleo de Pesquisa e Conservação de Cervídeos) of FCAV were used in this study. The animals were maintained in individual stalls and weighted in a transport box 15 days prior to the beginning of the experiment to estimate the anesthetic doses. After a 24-hour period without access to food and water, the animals were physically restrained (Duarte et al. 2001) and had their eyes and ears protected from outside stimulus. Then, the animals were anesthetized intravenously with ketamine ${ }^{4}(5 \mathrm{mg} / \mathrm{kg})$, xylazine ${ }^{5}(0.3 \mathrm{mg} / \mathrm{kg})$ and midazolam ${ }^{6}$ $(0.5 \mathrm{mg} / \mathrm{kg})$ previously combined in the same syringe. Afterwards, the animals were weighed again to determine if there was an alteration in their body weight. Subsequently, the animals were intubated with a 5-5.5 i.d. cuffed endotracheal tube using a laryngoscope and were placed in dorsal recumbency with the

\footnotetext{
${ }^{4}$ Dopalen, Vetbrands, Jacareí, Brazil.

5 Coopazine, Mallinckrodt Vet, Cotia, Brazil.

${ }^{6}$ Dormire, Cristália, Itapira, Brazil.
} 
posterior members tilted to an adjustable surgical table. All deer had the cephalic vein catheterized using 22-24 gauge catheter $^{7}$ and saline solution $(0.9 \% \mathrm{NaCl})$ administered at $10 \mathrm{~mL} / \mathrm{kg} / \mathrm{h}$ rate. Anesthesia was maintained with isoflurane ${ }^{8}$, which was diluted at $60 \mathrm{~mL} / \mathrm{min} / \mathrm{kg}$ flows of pure oxygen administered from a semi-closed circle breathing system with an out-of-circle vaporizer calibrated for isoflurane (HB Hospitalar, São Paulo, Brazil). Isoflurane concentration was adjusted to allow adequate surgical anesthetic plane, using Guedel's plane of anesthesia and a noxious stimulus of clamp interdigital region of posterior members using a haemostatic until the first stage of clamp, similar to described by Eger II et al. (1965). The animals were maintained in spontaneous ventilation during anesthesia.

Each animal underwent two laparoscopies, 40 days apart, to visualize their reproductive organs with abdominal $\mathrm{CO}_{2}$ insufflations. To evaluate the main events of laparoscopy the procedure was divided into three periods: animal without abdominal insufflation (P1), with abdominal insufflation (P2) and with abdominal insufflation with hips raised to $45^{\circ}$ (P3). In P3, as the surgical table was adjusted to $45^{\circ}$ the animals assumed the head-down position to perform the laparoscopic procedures. Eleven of the 12 laparoscopies proposed were successfully conducted, while one had to be replaced with a laparotomy due to a technical mistake that occurred during the surgical procedure. All animals submitted to laparoscopy received intravenous monophenilbutazone ${ }^{9} 4 \mathrm{mg} / \mathrm{kg}$ before surgical incision and intramuscular pentabiotic ${ }^{10} 40,000 \mathrm{Ul} / \mathrm{kg}$ of benzatine penicillin by the end of surgical procedures.

The control experiment was conducted 40 days after the last laparoscopy with the objective of establishing the effect of the anesthetic protocol on the animal without a surgical incision. For that, the same six animals were anesthetized again and placed in dorsal recumbency for a period similar to the average time under anesthesia required for the laparoscopy procedure. For data collection and comparison purposes, the anesthesia period for the controls was also divided into P1, P2 and P3 similarly to the average duration for each of the respective anesthesia periods during the laparoscopy. Since the effect of anesthetic protocol needs to be determined the surgical table was not elevated to $45^{\circ}$ in $\mathrm{P} 3$ during the control treatment.

During P1, P2 and P3 of both treatments, the $\mathrm{SpO}_{2}$ and RT were continuously monitored with a pulse-oximeter ${ }^{11}$ with probes attached to the ear and in the rectum, respectively. The HR was determined by auscultation of heart beats per minute using a stethoscope and the number of thoracic excursion determined the RR. All these parameters were recorded every 10 minutes during the periods mentioned.

At the end of the laparoscopy procedure, the isoflurane was interrupted; the animals were placed in right lateral recumbency in the recovery room, and the endotracheal tube removed after they had regained the deglutition reflex. The periods of time necessary to perform extubation (time of extubation) and for the animal to stand on its own (recovery time) were recorded. The quality of anesthetic recovery was observed and evaluated using the following scores based on the criteria: Excellent (when the animal stood up after the first attempt without any ataxia); Good (when the animal stood up after one or two attempts with little or no ataxia); Satisfactory (when the animal stood up after one to three attempts with prolonged ataxia); Moderate (when the animal tried to stand up after three or more attempts with prolonged ataxia with or without excitation); and Poor (when the animal tried to stand up after three or more attempts, with evident excitation and a high risk of injury).

Data were analyzed through the variance analysis test (Oneway ANOVA) followed by the Tukey test with SAS ${ }^{12}$. The results for the quality of the anesthetic recovery were analyzed by the non-parametric Kruskal-Wallis test, while the Wilcoxon test was used to analyze the multiple comparisons using the GraphPad Prism ${ }^{13}$. $\mathrm{P}$ values $>0.05$ were considered significant.

\section{RESULTS}

No significant difference $(P>0.05)$ was found between the animal's weights 15 days before the experiment (16.5 \pm $0.4 \mathrm{~kg}, \mathrm{M} \pm \mathrm{SE}$ ) and on the day of the experiment (16.1 \pm $0.4 \mathrm{~kg}$ ). The mean duration time for the 11 laparoscopies conducted on the six brown brocket deer was $51 \pm 4 \mathrm{~min}$ and the mean duration time of P1, P2 and P3 were $31.6 \pm$ $5.6,14.6 \pm 9.8$ and $28.2 \pm 8.0 \mathrm{~min}$, respectively. The mean for $\mathrm{CO}_{2}$ pressure used during the laparoscopies (P3) was $14.2 \pm 2.39 \mathrm{mmHg}$.

An adequate anesthetic plane was obtained to perform the laparoscopy and control. The mean concentration of the isoflurane to anesthetic maintenance was $0.78 \pm 0.08 \%$ for the animals submitted to control and $0.89 \pm 0.08 \%$ for the laparoscopies. However, all animals regurgitated when submitted to P3 during the laparoscopic procedures. One of the animals submitted to the control treatment became hypothermic $\left(35.0^{\circ} \mathrm{C}\right)$. Two animals that underwent laparoscopies showed HR below 60 beats per minute during the anesthetic recovery and they received atropine sulfate at $0.04 \mathrm{mg} / \mathrm{kg}$ i.v.

The extubation mean times and recovery mean times were $14 \pm 7 \mathrm{~min}$ and $43 \pm 10 \mathrm{~min}$ for the control treatment and $18 \pm 4 \mathrm{~min}$ and $39 \pm 8 \mathrm{~min}$ for the laparoscopy, respectively. No significant differences $(P>0.05)$ were found between the concentration of isoflurane used and the recovery and extubation mean time when the control and laparoscopic procedures were compared.

Moreover, no significant differences were found between the HR, RR, $\mathrm{SpO}_{2}$ and RT of the control when compared to laparoscopy in any of the periods tested (Table 1). However, the mean of the RR between the P1 and P3, independent of the laparoscopy, decreased significantly $(\mathrm{P}<0.05)$ (Fig.1). Likewise, $\mathrm{RT}$ decreased significantly between P1, P2 and P3, independent of the laparoscopy $(\mathrm{P}<0.05)$ (Fig.2).

Significant differences were observed between control and laparoscopy for the sedation recovery conditions. The majority of the animals had Good scores for the control,

\footnotetext{
${ }^{7}$ Angiocath, Bencton Dickinson and Company ${ }^{\circledR}$, São Paulo, Brazil.

${ }^{8}$ Forane, Abbott $^{\circledR}$, São Paulo, Brazil.

${ }^{9}$ Monofenil, Vetnil, São Paulo, Brazil.

10 Pentabiótico, Bayer, São Paulo, Brazil.

${ }^{11}$ SDI VetOx Plus 4700 and 4404, Heska Corporation, Waukesha, WI 53188, USA.

12 SAS Institute Inc., Cary, NC, USA.

${ }^{13}$ GraphPad Software Inc., San Diego, CA, USA.
} 
Table 1. Effect of laparoscopy on the heart rate (HR), respiratory rate (RR), rectal

temperature (RT) and oxyhemoglobin saturation $\left(\mathrm{SpO}_{2}\right)$ in brown brocket deer (Mazama gouazoubira) anesthetized with a mixture of ketamine/xylazine/midazolam and isoflurane for three different periods: animal without abdominal insufflation (P1), with abdominal $\mathrm{CO}_{2}$ insufflation (P2) and with abdominal $\mathrm{CO}_{2}$ insufflation with the hips raised at $45^{\circ}(\mathrm{P} 3)$. Data are expressed as mean and standard error (SE)

\begin{tabular}{lccccccc}
\hline \multirow{2}{*}{ Parameters } & \multicolumn{3}{c}{ Control $(\mathrm{n}=6)$} & & \multicolumn{3}{c}{ Laparoscopy $(\mathrm{n}=6)^{\mathrm{a}}$} \\
\cline { 2 - 4 } \cline { 6 - 8 } & $\mathrm{P} 1$ & $\mathrm{P} 2$ & $\mathrm{P} 3$ & & $\mathrm{P} 1$ & $\mathrm{P} 2$ & P3 \\
\hline RR (breath/min) & $37.3 \pm 6.7$ & $35.3 \pm 6.8$ & $32.5 \pm 6.4$ & & $40.3 \pm 6.3$ & $36.7 \pm 5.6$ & $32.8 \pm 7.8$ \\
HR (beats/min) & $100.5 \pm 8.1$ & $102.7 \pm 9.1$ & $101.8 \pm 7.7$ & & $116.3 \pm 6.3$ & $110.3 \pm 9.1$ & $101.7 \pm 8.0$ \\
RT $\left({ }^{\circ} \mathrm{C}\right)$ & $38.0 \pm 0.2$ & $37.5 \pm 0.3$ & $36.9 \pm 0.4$ & & $38.4 \pm 0.2$ & $37.8 \pm 0.2$ & $37.3 \pm 0.2$ \\
$\mathrm{SpO}_{2}(\%)^{\mathrm{b}}$ & $94.5 \pm 1.7$ & $94.2 \pm 1.6$ & $94.1 \pm 1.6$ & & $94.5 \pm 0.8$ & $96.1 \pm 0.7$ & $94.6 \pm 0.7$
\end{tabular}

a Data from the 11 laparoscopies conducted in six animals.

b Values measured through the pulse oximeter.

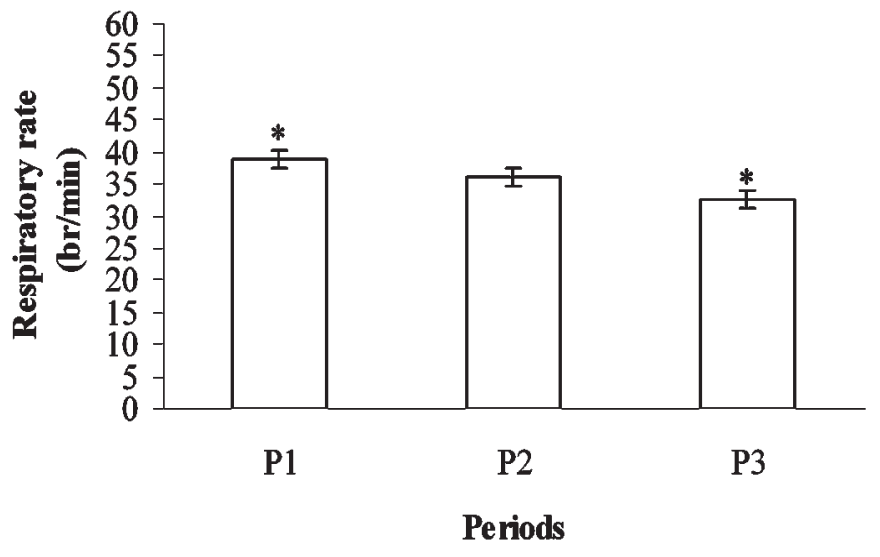

Fig.1. Reduction of the respiratory rate of brown brocket deer (Mazama gouazoubira) during the anesthesia conducted with ketamine/xylazine/midazolam combination and isoflurane. Data are expressed by the mean and standard error of the respiratory rate that occurred during three different periods, P1, P2 and P3, regardless of treatments. ${ }^{*} \mathrm{P}<0.05$ through Tukey test.

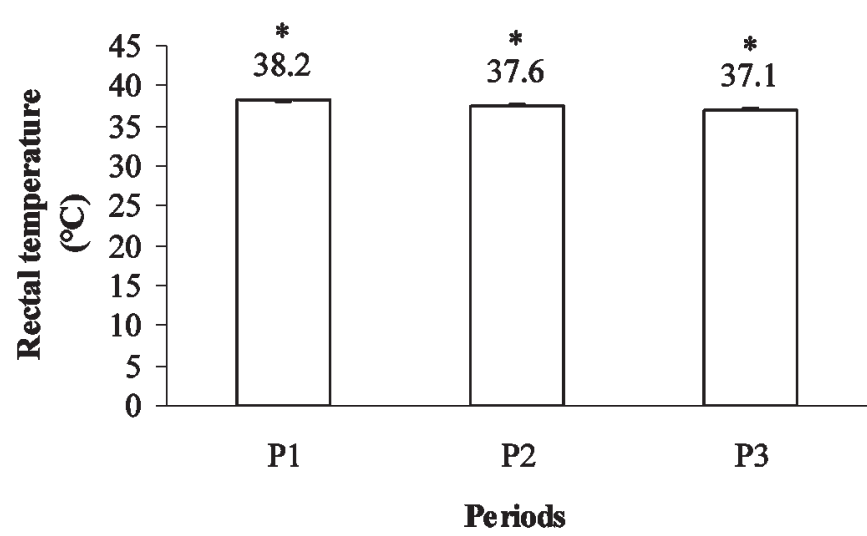

Fig.2. Reduction of the rectal temperature of brown brocket deer (Mazama gouazoubira) during the anesthesia conducted with ketamine/xylazine/midazolam combination and isoflurane. Data are expressed by the mean and standard deviation of the rectal temperature that occurred during three different periods, $\mathrm{P} 1, \mathrm{P} 2$ and $\mathrm{P} 3$, regardless of treatments. ${ }^{*} \mathrm{P}<0.05$ through Tukey test.

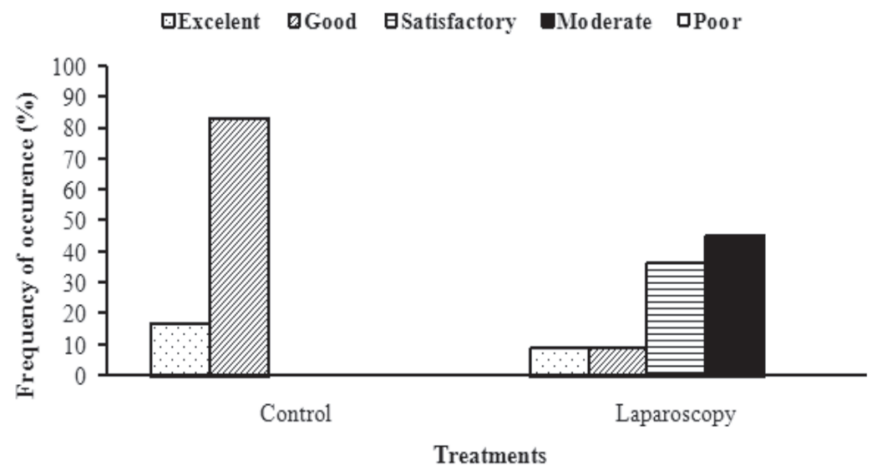

Fig.3. Effect of laparoscopy on the scores of the anesthetic recovery. $\mathrm{P}<0.05$ by the Kruskal-Wallis test.

while Moderate was the prevailing score for the animals that underwent the laparoscopy treatment (Fig.3).

\section{DISCUSSION}

The current study evaluated the effects of laparoscopy on the cardiorespiratory system $\left(\mathrm{HR}, \mathrm{RR}\right.$, and $\left.\mathrm{SpO}_{2}\right)$ and the rectal temperature (RT) of female brown brocket deer anesthetized with ketamine/xylazine/midazolam combination and isoflurane. The main result found was the absence of any significant alterations in the $\mathrm{HR}, \mathrm{RR}, \mathrm{SpO}_{2}$ and the RT during P1, P2 and P3 as a result of laparoscopy procedures, although a slight decrease of RR and a reduction of the RT were observed probably due to the anesthesia.

The abdominal $\mathrm{CO}_{2}$ insufflation at an intra-abdominal pressure of approximately $14 \mathrm{mmHg}$ used in this study did not cause a significant alteration in heart rate (HR). These results corroborated those found for domestic species (Ishizaki et al. 1993, Liem et al. 1994, Rademarker et al. 1995, Cruz et al. 1996) and other wild species (Reedy et al. 1995, Posner et al. 2005) that received abdominal $\mathrm{CO}_{2}$ insufflation at intra-abdominal pressure of up to $20 \mathrm{mmHg}$ and did not show a significant alteration in HR. Some reports showed that just intra-abdominal $\mathrm{CO}_{2}$ pressures higher than $20 \mathrm{mmHg}$ could promote significant alterations in the vascular peripheral resistance and in the visceral blood flow capable of affecting the HR (Ho et al. 1995, Klopfens- 
tein et al. 1998). In contrast, increasing in HR during the abdominal $\mathrm{CO}_{2}$ insufflation at intra-abdominal pressure of $15 \mathrm{mmHg}$ was reported in pigs, but this was associated with pharmacological effects of $\mathrm{CO}_{2}$ due to its high absorption in blood and not because of intra-abdominal pressure (Ho et al. 1995). In this experiment neither $\mathrm{PaCO}_{2}$ nor $\mathrm{ETCO}_{2}$ was measured and the evaluation of a possible $\mathrm{CO}_{2}$ absorption was not performed.

The abdominal $\mathrm{CO}_{2}$ insufflation during the $\mathrm{P} 2$ and $\mathrm{P} 3$ did not cause significant alterations in RR of brown brocket deer. These findings agree with a study conducted with llama (Llama glama), which showed that the dorsal position of the animal during intra-abdominal insufflation using $\mathrm{CO}_{2}$ did not significantly alter the RR (Lin et al. 1997). On the other hand, a reduction in respiratory amplitude was visually observed during the P3 in animals submitted to laparoscopy.

The laparoscopy did not significantly alter the RR when compared to the control treatment; however, a slight reduction in the respiratory function of animals was recorded, which was due to the significant difference of the RR mean found between the P1 and P3 periods in both treatments. This indicates a probable depression of the respiratory centers caused by the drugs used during the anesthesia or a decrease of ventilatory capacity due to dorsal recumbency position.

Although there are no reports in the literature about the effects of the chemical restraint protocol used in this study on the respiratory system of brown brocket deer, the association of xylazine with ketamine has been used for surgical anesthetic protocols for other species of cervids (Galka et al. 1999) and wild ungulates (Forster 1999), and it does not appear to promote a significant RR decrease, however hypoventilation and hypoxemia in North American cervids can occur (Caulkett 1997). Midazolam, when associated with ketamine, can cause bradypnea and subsequent hypercarbia as observed for equine (Luna et al. 1997), since this drug depresses the respiratory centers of the brain. Moreover, inhaled drug as isoflurane promotes dose-dependent respiratory depression, which is influenced by the sedation period (Eger II 1981).

Despite a significant reduction of the respiratory rate, this effect did not promote significant alterations in $\mathrm{SpO}_{2}$ during the laparoscopy and control treatments. This suggests a slight respiratory depression using non-invasive pulse-oximeter monitoring method; however this must be better investigated in further studies using hemogasometry analyses, since this monitoring method is considered less accurate than the hemogasometry to detect hypoxemia (Grosenbaugh \& Muir 1998).

It was recorded that laparoscopic insufflation of abdominal cavity could induce hyperthermia in pigs and human beings (Bessell et al. 1995). However, the significant reduction of the rectal temperature found between $\mathrm{P} 1, \mathrm{P} 2$ and P3 in this study occurred independent of the laparoscopy treatment, and caused hypothermia $\left(35^{\circ} \mathrm{C}\right)$ during the recovery of one animal. This result might be related with the depression of the thermoregulatory centers present in the hypothalamus and the muscle relaxant activity that occurred during anesthesia with $\alpha-2$ agonist and anxiolytic drugs (Klein \& Klide 1989). Studies conducted with fallow deer (Cervus dama) showed that the decrease in the RT was caused by the $\alpha-2$ agonist drug and by the immobility of the animal during the anesthesia with ketamine/xylazine (Galka et al. 1999). A similar result was found for the white-tailed deer (Odocoileus virginianus) during the sedation with xylazine (Roughton 1975), thus confirming the influence of these drugs on animal thermoregulation. The findings reported in the present study agree with those from the literature, even though lower doses of xylazine were administered to the test animals. The decreased in the RT observed in brown brocket deer could also be caused by the use of midazolam, since it is known that the administration of this drug in humans can cause dose-dependent lowering of the body temperature (Matsukawa et al. 1997). Therefore, a synergism between these drugs may have caused a significant reduction of the RT during the sedation of the brown brocket deer in this study associated to respiratory heat loss and immobility during anesthesia.

The anesthetic recovery conditions proposed did not directly evaluate the pain caused by the surgical trauma; however, the high frequency of Moderate recoveries observed for the laparoscopy treatment suggests that the pain could have influenced the quality of the anesthetic recovery. The higher number of standing attempts of the animals after the laparoscopy may indicate pain related to the surgical trauma, although no significant difference was found for the recovery time when compared to the control treatment.

The results reported in this study led to the conclusion that laparoscopy with abdominal $\mathrm{CO}_{2}$ insufflation $(10 \mathrm{~mm}$ $\mathrm{Hg}$ ) used to visualize the reproductive organs of brown brocket deer sedated with an association of ketamine/ xylazine/midazolam and maintained with isoflurane can be safely conducted. This conclusion is based on the fact that no significant alterations to the $\mathrm{HR}, \mathrm{RR}, \mathrm{SpO}_{2}$ and $\mathrm{RT}$ were recorded between animals submitted to laparoscopies and control. However, the laparoscopy procedure should be closely and constantly monitored given that the anesthesia with these drugs can cause bradypnea and hypothermia in brown brocket deer.

Acknowledgements.- To Dr. Genner T. Pereira, for his help with the statistic analysis, and Dr. Mariângela Pereira de Pinho, for her assistance in the development of the anesthetic recovery scores used in this study. We are also grateful to the Roberto G. Trovati (MS), Bruna F. Polegato (MS), Clara M. de S. Camargo (DVM), Vanessa V. Abril (MS), and the technical team of Nupecce.

\section{REFERENCES}

Asher G.W., Monfort S.L. \& Wemmer C. 1999. Comparative reproductive function in cervids: implications for management of farm and zoo populations. J. Reprod. Fertil. 54(Suppl.):143-156.

Berg D.K. \& Asher G.W. 2003. New developments reproductive technologies in deer. Theriogenology 59(1):189-205. 
Bessell J.R., Karatassas A., Patterson J.R., Jamieson G.G. \& Maddern G. J. 1995. Hypothermia induced by laparoscopic insufflation. Surg. Endosc. 9:791-796.

Caulkett N.A. 1997. Anesthesia in North American cervids. Can. Vet. J. 38(6):389-390.

Cruz A.M., Sautherland L.C., Duke T., Townsend H.G., Ferguson J.G. \& Crone L.A. 1996. Cardiovascular carbon dioxide insufflation in the pregnant ewe: Uterine blood flow, intraaminiotic pressure, and cardiopulmonary effects. Anesthesiology 85(6):1395-1402.

Dias J.L.C. 1997. Miopatia de captura, p.172-179. In: Duarte J.M.B. (Ed.), Biologia e Conservação de Cervídeos Sul-Americanos: Blastocerus, Ozotocerus e Mazama. Funep, Jaboticabal, SP.

Duarte J.M.B., Merino M.L., Gonzáles S., Nunes A.L.V., Garcia J.M., Szabó M.P.J., Pandolfi J.R., Arantes I.G., Nascimento A.A., Machado R.Z., Araújo Jr J.P., Catão-Dias J.L., Werther K., Garcia J.E., Gírio R.J.S. \& Matushima E.R. 2001. Order Artiodactyla, family Cervidae (deer), p.402-422. In: Fowler M.E. \& Cubas Z.S. (Ed.), Biology, Medicine, and Surgery of South American Wild Animals. Iowa State University Press, Ames.

Duke T., Cruz A.M., Cruz J.I. \& Howden K.J. 2002. Cardiopulmonary effects associated with head-down position in halothane-anesthetized ponies with or without capnoperitoneum. Vet. Anesth. Analg. 29(2):76-89.

Eger II E.I. 1981. Isoflurane: A review. Anesthesiology. 55(5):559-576.

Eger II E.I., Saidman L.J. \& Brandstater B. 1965. Minimum alveolar anesthetic concentration: a standard of anesthetic potency. Anesthesiology 26(6):756-763.

Foster C.A. 1999. Immobilization of goitred gazelles (Gazelle subgutterosa) and Arabian mountain gazelles (Gazella gazella) with xylazine-ketamine. J. Zoo Wildl. Med. 30(3):448-450.

Galka M.E., Aguilar J.M., Quevedo M.A., Santisteban J.M. \& GómezVillamandos R.J. 1999. Alpha-2 agonist dissociative anesthetic combinations in fallow deer (Cervus dama). J. Zoo Wildl. Med. 30(3):451-453.

Grosenbaugh D.A. \& Muir W.W. 1998. Accuracy of noninvasive oxyhemoglobin saturation, end-tidal carbon dioxide concentration, and blood pressure monitoring during experimentally induced hypoxemia, hypotension, or hypertension in anesthetized dogs. Am. J. Vet. Res. 59(2):205-212.

Hendrix P.K. 2006. Anesthetic management of an orangutan (Pongo abeliipygmaeus) undergoing laparoscopic tubal ligation. J. Zoo Wildl. Med. 37(4):531-534.

Ho H.S., Saunders C.J., Gunther R.A. \& Wolfe B.M. 1995. Effects of hemodynamics during laparoscopy: $\mathrm{CO}_{2}$ absorption or intra-abdominal pressure? J. Surg. Res. 59(4):497-503.

Ishizaki Y., Bandai Y., Shimomura K., Abe H., Ohtomo Y. \& Idezuki Y. 1993. Safe intraabdominal pressure of carbon dioxide pneumoperitoneum during laparoscopic surgery. Surgery 114(3):549-554.
Klein L.V. \& Klide A.M. 1989. Central $\alpha-2$ adrenergic and benzodiazepine agonist and their antagonists. J. Zoo Wildl. Med. 20(2):138-153.

Klopfenstein C., Morel D.R., Clergue F. \& Pastor C.M. 1998. Effects of abdominal $\mathrm{CO}_{2}$ insufflation and changes of position on hepatic blood flow in anesthetized pigs. Am. J. Physiol. Heart Circ. Physiol. 275(3):900-905.

Liem T., Applebaum H. \& Herzberger B. 1994. Hemodynamic and ventilatory effects of abdominal $\mathrm{CO}_{2}$ insufflation at various pressures in the young swine. J. Pediatr. Surg. 29(8):966-999.

Lin H., Baird A.N., Pugh D.G., Anderson D.E. \& Gaughan E.M. 1997. Effects of carbon dioxide insufflation combined with changes in body positions on blood gas and acid-base status in anesthetized Llamas (Llama glama). Vet. Surg. 26(5):444-450.

Luna S.P., Taylor P.M. \& Massone F. 1997. Midazolam and ketamine induction before halothane anaesthesia in ponies: cardiorespiratory, endocrine and metabolic changes. J. Vet. Pharmacol. Therap. 20(2):153-159.

Matsukawa T., Hanagata K., Ozaki M., Iwashita H., Koshimizu M. \& Kumazawa T. 1997. I.m. midazolam as premedication procedures a concentration-dependent decrease in core temperature in male volunteers. Brit. J. Anaesth. 78(4):396-399.

Posner L.P., Woodie J.B., Curtis P.D., Erb H.N., Gilbert R., Adams W.A. \& Gleed R.D. 2005. Acid-base, blood gas, and physiologic parameters during laparoscopy in the head-down position in white-tailed deer (Odocoileus virginianus). J. Zoo Wildl. Med. 36(4):642-647.

Quandt J.E. 1999. Anesthetic consideration for laser, laparoscopy, and thoracoscopy procedures. Clin. Tech. Small. Anim. Pract. 14(1):50-55.

Randemaker B.M.P., Meyer D.W., Bannenberg J.J.G., Klopper P.J. \& Kalkman C.J. 1995. Laparoscopy without pneumoperitoneum. Surg. Endosc. 9:797-801.

Reedy M.B., Galan H.L., Carnes A., Knight A.B. \& Kuebl T.J. 1995. Maternal and fetal effects of laparoscopic insufflation in the gravid baboon. J. Am. Assoc. Gynecol. Laparosc. 2(4):399-406.

Roughton R.D. 1975. Xylazine as an immobilizing agent for captive whitetailed deer. J. Am. Vet. Med. Assoc. 167(7):574-576.

Sumar J. \& Bravo P.W. 1991. In situ observation of the ovaries of llamas and alpacas by use of a laparoscopic technique. J. Am. Vet. Med. Assoc. 199(9):1159-1163.

Willard S.T., Flores-Foxworth G., Chapman S., Drew M.L., Hughes D.M., Neuendorff D.A. \& Randel R.D. 1998. Hybridization between wapiti (Cervus elaphus manitobensis) and sika deer (Cervus Nippon): a comparison of two artificial insemination techniques. J. Zoo Wildl. Med. 29(3):295-299.

Zanetti E.S. 2006. Comparação de dois métodos para sincronização do ciclo estral em veado-catingueiro (Mazama gouazoubira). Dissertação de Mestrado, Faculdade de Ciências Agrárias e Veterinárias, Universidade Estadual Paulista, Jaboticabal, SP. 54p. 